\section{A note on the population structure of leopards (Panthera pardus) in South Africa}

\author{
Laura Tensen $^{1 *}$, Dick Roelofs ${ }^{2} \&$ \\ Lourens H. Swanepoel ${ }^{3,4}$ \\ ${ }^{1}$ Department of Zoology, Faculty of Science, University of \\ Johannesburg, South Africa \\ ${ }^{2}$ Department of Ecological Science, Section Animal Ecology, \\ Vrije University, Amsterdam, Netherlands \\ ${ }^{3}$ Centre for Wildlife Management, Hatfield Experimental Farm, \\ University of Pretoria, Private Bag X20, Hatfield, 0028 South Africa \\ ${ }^{4}$ School of Mathematical and Natural Sciences, University of \\ Venda, Private Bag X5050, Thohoyandou, 0950 South Africa \\ Received 6 June 2013. Accepted 25 March 2014
}

\section{INTRODUCTION}

The leopard (Panthera pardus) occurs throughout Africa and Asia, although their range in Africa has declined by $37 \%$ in the last century (Ray et al. 2005). The main factors contributing to the decline in leopard distribution seem to be a combination of habitat destruction, human persecution, and prey depletion (Henschel et al. 2011). These activities have increased habitat fragmentation and can affect leopard behaviour through home range shifts and limited dispersal (Ngoprasert et al. 2007).

Limited dispersal, and hindered gene flow, can decrease genetic variation and increase genetic differentiation in fragmented subpopulations due to inbreeding, genetic drift and selection (Haag et al. 2010). Lowered genetic diversity may in turn cause reduced survival and reproduction success because of increased accumulation of deleterious mutations and increased probabilities in allele loss (Whitlock 2000; Reed \& Frankham 2003; Frankham et al. 2004).

Recent work indicates that suitable leopard habitat in South Africa has become fragmented (Swanepoel et al. 2013), which could potentially lead to limited leopard dispersal and depleted genetic diversity. However, leopards are one of the most opportunistic large predators in Africa, which allows them to disperse through modified and unsuitable habitats (Marker \& Dickman 2005). Nonetheless, a recent genetic study on Indian leopards ( $P$. pardus fusca) showed increased genetic differentiation associated with habitat fragmentation, indicating restricted

*To whom correspondence should be addressed. E-mail: tensen.laura@gmail.com dispersal (Dutta et al. 2013a). These findings, combined with the suggested fragmentation of South African leopard habitat, highlights the importance of an understanding of leopard population structure in South Africa.

The main objective of this study was to identify genetic structuring and diversity patterns among leopard populations in South Africa to assess whether dispersal still occurs. We adapted the suitable leopard habitat map from Swanepoel et al. (2013) to delineate four core areas and we hypothesised that genetic differentiation between these leopard populations is likely to exist (Fig. 1).

\section{METHODS}

Specimens were retrieved from museums, taxidermists and biologists, and brought to the molecular laboratory of the Department of Animal Ecology at the VU University of Amsterdam. The samples were cut and ground, cooled with nitrogen and admixed with $100 \mu \mathrm{l}$ PBS in order to pulverize the material. For DNA extraction of skin and skull tissue, the Promega SV protocol and DNA IQTM System bone isolation protocol were used respectively (DNA IQTM System Database Protocol Technical Bulletin, TB297, 2009).

Polymerase chain reaction (PCR) amplification followed, for which the protein-coding NADH-5 gene (311 bp; F:GTGCAACTCCAAATAAAAG; R:GGGTCTGAGTTTATATATC) and non-coding central conserved region of the D-loop (349 bp; F:TCAACTGTCCGAAAGTGCTT; R:CCTGTG GAAGCAATAGGAATT) were used. PCR reactions $(25 \mu \mathrm{l})$ were prepared for each sample with $13.3 \mu \mathrm{l}$ $\mathrm{H}_{2} \mathrm{O} ; 5 \mu \mathrm{l} 5 \mathrm{x} \mathrm{GoTaq}^{\circledast}$ Flexi Reaction Buffer; $1.5 \mu \mathrm{l}$ $\mathrm{MgCl}_{2}$ Solution $(25 \mathrm{mM}) ; 2 \mu \mathrm{l}$ dNTPs $(2.5 \mathrm{mM}$ each); $1 \mu \mathrm{l}$ of each forward and reserve primer (5 $\mu \mathrm{M}$ each); $0.2 \mu \mathrm{l}$ of GoTaq ${ }^{\oplus}$ DNA Polymerase (5 $\mathrm{U} / \mathrm{\mu l}$ ); $0.02 \mu \mathrm{l}$ of $P f u$ DNA Polymerase (Promega, 2-3 $\mathrm{U} / \mu \mathrm{l})$; and $1 \mu \mathrm{l}$ of genomic DNA.

Amplification reactions were run in a Biometra T3 Thermocycler, with an initial denaturation step of $95^{\circ} \mathrm{C}$ for $3 \mathrm{~min}$, followed by 40 cycles of denaturation at $95^{\circ} \mathrm{C}$ for $30 \mathrm{~s}$, annealing at $53^{\circ} \mathrm{C}$ for $45 \mathrm{~s}$, extension at $72^{\circ} \mathrm{C}$ for $45 \mathrm{~s}$, and a final elongation step at $72^{\circ} \mathrm{C}$ for $10 \mathrm{~min}$. The DNA yield was verified on an agarose gel. The cycle-sequencing PCRs were performed with a total volume of $10 \mu \mathrm{l}$, of which $1.0 \mu \mathrm{l}$ consisted of the DNA template, $1.5 \mu \mathrm{l}$ $5 \times$ sequencing buffer (Applied Biosystems), $1.0 \mu \mathrm{l}$ primer $(5 \mu \mathrm{M}), 1.0 \mu \mathrm{l} \mathrm{Big} \mathrm{Dye}{ }^{\circledast}$ ready reaction mix (Applied Biosystems) and $5.5 \mu \mathrm{H} \mathrm{H}_{2} 0$. Cyclesequencing PCRs were run with $96^{\circ} \mathrm{C}$ for $1 \mathrm{~min}$, 


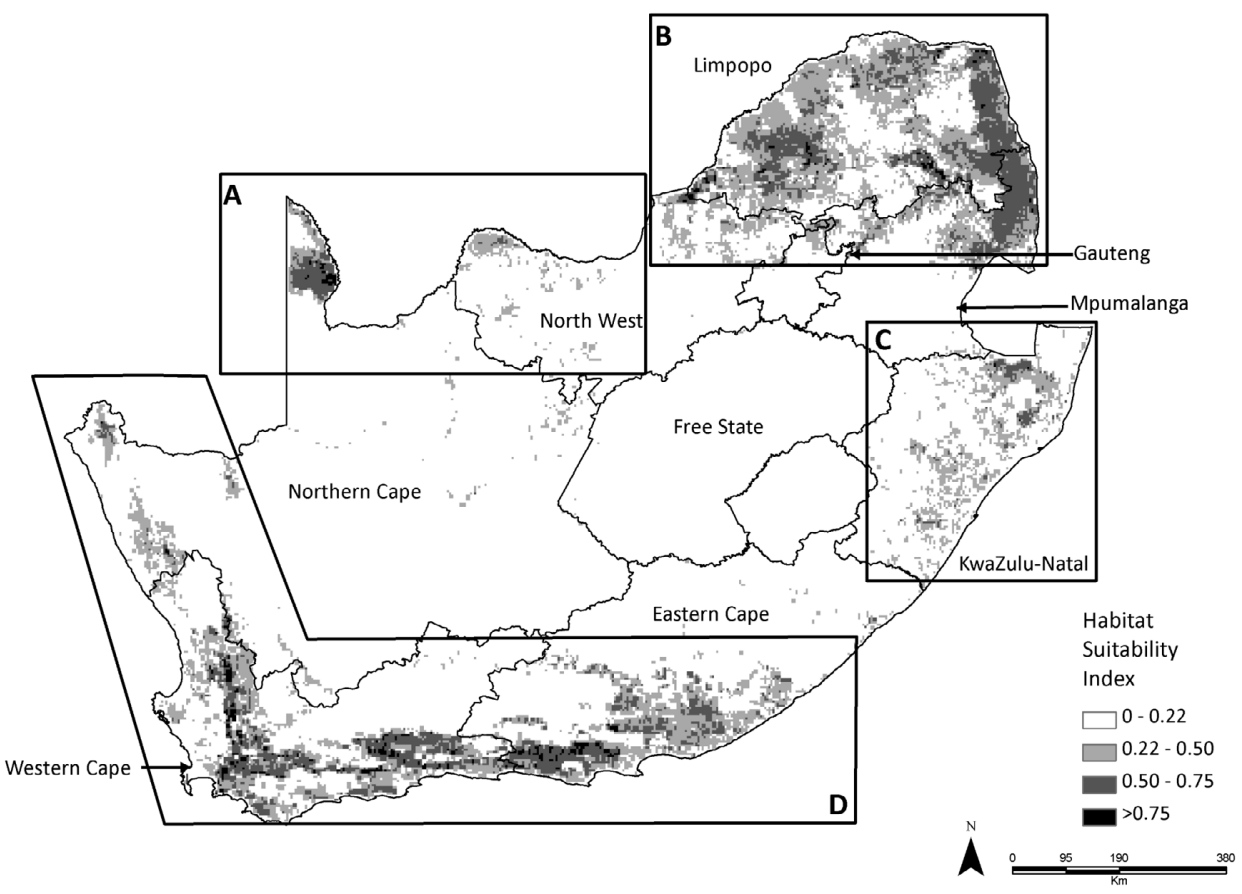

Fig. 1. The suitable leopard habitat map from Swanepoel et al. (2013) adapted to delineate four potential isolated core areas: north western population (A), Limpopo population (B), KwaZulu-Natal (C), and southern population (D). DNA samples from $A$ and $B$ were joined to form the northern population.

25 cycles of $96^{\circ} \mathrm{C}$ and $52^{\circ} \mathrm{C}$ for $10 \mathrm{~s}$, and $60^{\circ} \mathrm{C}$ for $90 \mathrm{~s}$. Following purification methods, PCR products were sequenced on a 16-capillary DNA Sanger Sequencer (ABI 3100).

Sequences were verified with BLAST (Basic Local Alignment Search Tool; Altschul et al. 1990) in order to edit and assemble them, using the computer program Vector NTI (Invitrogen; Lu \& Moriyama 2004). Sequences were aligned using the software of ClustalW and both markers were concatenated for further analysis. This joined fragment was analysed using the computer program MEGA (Molecular Evolutionary Genetics Analysis: Kumar et al. 1993). Pairwise distances were computed with the Kimura 2-parameter model (Kimura 1980), and differences among populations were tested with a one-way ANOVA in SPSS Statistics 17.0. Phylogenetic relationships of the obtained populations were calculated using neighbour-joining and maximum likelihood. Reliabilities of phylogenetic groupings were estimated by 1000 bootstrap replicates.

\section{RESULTS}

Seventeen specimens from the Western Cape and three samples from the Eastern Cape were used for DNA analyses and clustered into the southern leopard population. Twenty-one samples were successfully analysed from the Waterberg (Limpopo province) and united with three samples from the Northern Cape into the northern leopard population. Sequences from the NADH- 5 fragment (311 bp) and D-loop (349 pb) were concatenated, resulting in a total of 660 base pairs when primers were cut off. A total of 146 variable sites and 541 conserved nucleotide sites were detected.

The total fragment was used to analyse the genetic distances and the coefficients of gene variation in the South African leopard populations. Because too few samples were available to compare all populations, correlation between the southern (Western and Eastern Cape) and northern leopards (Northern Cape and Limpopo) was calculated separately as a measure for genetic distance. There was a significantly $(P=0.005)$ higher correlation within the southern populations, which indicates that there is less genetic variation in this area.

Phylogenetic analyses were performed for the concatenated fragment, and both methods generated consistent branching patterns. The phylogenetic tree obtained from the neighbour-joining 


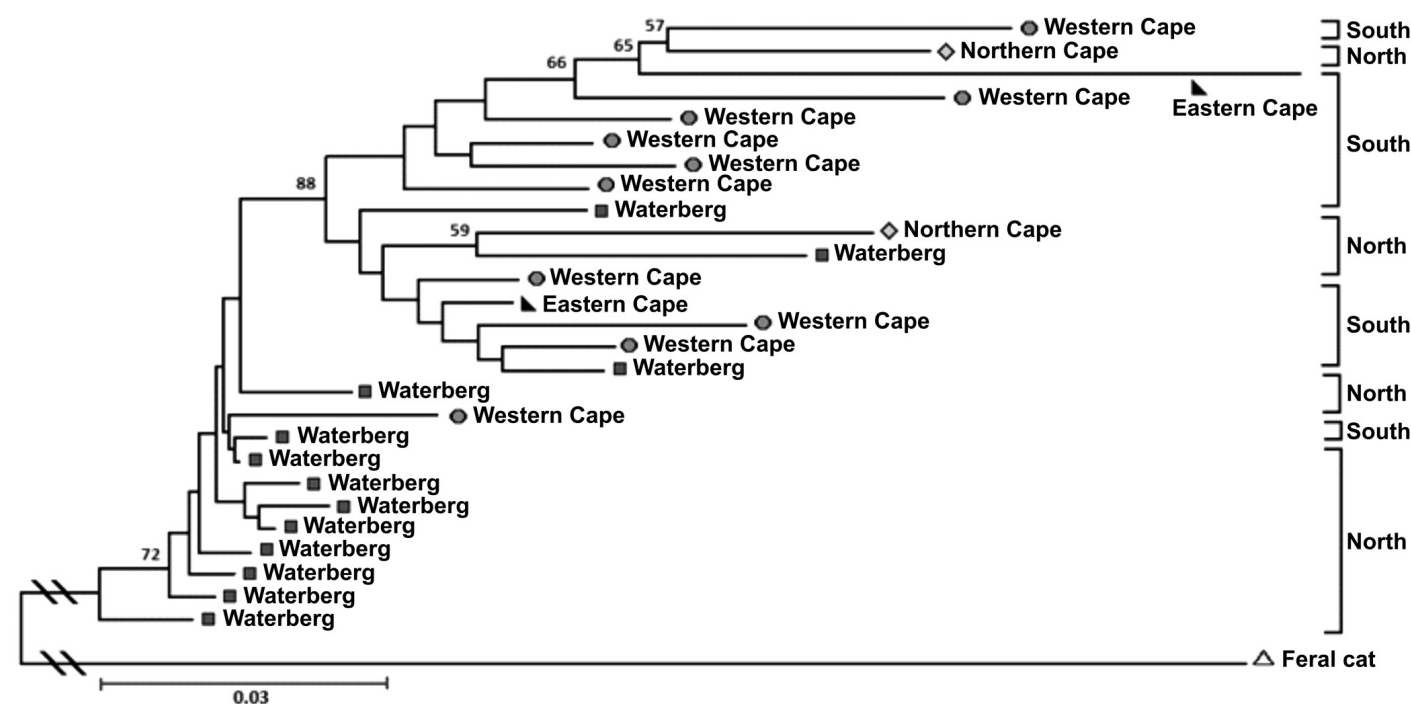

Fig. 2. Phylogenetic relationships among four populations of leopard (Panthera pardus) in South Africa: Western Cape and Eastern Cape (south), Waterberg and Northern Cape (north). The results were obtained by neighbourjoining, from concatenated NAHD-5 and D-loop fragments (660 bp). Reliability of the tree was 1000 bootstrap replicates. The feral cat (Felis catus) was used as outgroup.

analysis (Fig. 2) illustrates bootstrap values above fifty percent along the branching patterns, as only these are reliable enough for phylogenetic inference.

The neighbour-joining tree shows no distinction between southern and northern leopards, and some leopards originating from Waterberg were found among populations from the Western Cape. Moreover, each individual exerted a unique haplotype and no identical haplotypes were shared among different leopard samples. Hence, within-population variation is substantial for both the southern and the northern leopard populations, despite the genetic distance analysis showing repressed variation among southern leopards. The difference in branching length is also an indication of high genetic diversity with regard to the NADH-5 gene locus.

\section{DISCUSSION}

Phylogenetic analyses and genetic distance analyses suggest that leopards in southern and northern South Africa are genetically homogenous. Our results thus suggest that gene flow is likely to occur between the two sampled populations, which is indicative of dispersal. However, we found that genetic distances amongst southern leopards were small compared to northern populations, which could indicate restrained gene flow. Nevertheless, lower genetic diversity can also be explained by the fact that southern populations only have one potential immigration route to maintain their diversity: from northern South Africa. Northern leopard populations, on the other hand, could potentially receive new genes from Zimbabwe, Botswana, Mozambique and the southern parts of South Africa.

Results from the phylogenetic analyses indicated very little clustering and only two of the clustered groups were supported by a bootstrapping value above 50 . This suggests that all sampled leopards were more or less genetically homogenous. Our results concur with Spong et al. (2000) who found high levels of heterozygosity and no significant genetic structuring of fragmented leopard populations in Tanzania. Another explanation of population admixture might be that the relevant leopards were translocated from one location to another, which has been a common management procedure for large South African carnivores (Lindsey et al.2009).

Dutta et al. (2013a,b) showed that leopards can be affected by habitat fragmentation and a lack of dispersal. They illustrated that despite of population admixture and high levels of genetic diversity, genetic sub-structuring still occurred. The lower genetic differences we detected among southern leopards indicates that genetic structuring in South Africa is probable. We suggest that such structuring can be due to two, not necessary mutually exclusive, reasons. Firstly, genetic isola- 
tion can be due to habitat loss and the associated fragmentation. Recent analysis (Swanepoel et al. 2013) highlighted the fragmentation of suitable leopard habitat in the southern parts of South Africa. Secondly, increased genetic isolation can also be caused by increased retaliatory killing and poorly managed trophy harvesting (Stoner et al. 2012). The Western and Eastern Cape provinces have long histories of leopard livestock conflict (Conradie 2012) and a large proportion of female $(35 \%)$ and subadult leopards $(28 \%)$ are killed in retaliatory actions (Swanepoel et al., in press). Poorly managed trophy harvesting (e.g. $32 \%$ of females are harvested, which is particularly detrimental to population persistence; Dalerum et al. 2008) can further impact survival rate and dispersal ability of leopard populations in South Africa (Loveridge et al. 2009).

Based on the results of this study population admixture seems to occur frequently enough to avoid inbreeding, the loss of genetic diversity and genetic differentiation. No populations appear to be isolated, yet the results should be interpreted cautiously because not all core areas are included in the dataset and sample sizes from most representative populations were small. Moreover, as southern populations already show clustering and increased genetic correlation, they might be on their way of becoming isolated. Our study lacked the fine-scale resolution needed to detect population structure and we suggest that future studies should aim to collect genetic data from more populations to see if nearby populations have a smaller genetic distance (Kimura \& Weiss 1964).

L.H.S was supported by NRF doctoral (No. 74819) and postdoctoral grants (No. 88179), and L.T. by research funds available at the Vrije University Amsterdam. We thank the nature conservation authorities and Lajuma Research Centre for collection of genetic material and use of facilities.

\section{REFERENCES}

ALTSCHUL, S.F., GISH, W., MILLER, W., MYERS, E.W. \& LIPMAN, D.J. 1990. Basic local alignment search tool. J. Mol. Biol. 215: 403-410.

CONRADIE, B. 2012. Are hunting clubs the solution to small stock depredation? The case of Ceres, 1979 and 1980. Agrekon 51: 96-113.

DALERUM, F., SHULTS, B. \& KUNKEL, K. 2008. Estimating sustainable harvest in wolverine populations using logistic regression. J. Wild. Manage. 72: $1125-1132$.

DUTTA, T., SHARMA, S., MALDONADO, J.E., WOOD, T.C., PANWAR, H.S. \& SEIDENSTICKER, J. 2013a. Fine-scale population genetic structure in a wide- ranging carnivore, the leopard (Panthera pardus fusca) in central India. Divers. Distrib. 19: 760-771.

DUTTA, T., SHARMA, S., MALDONADO, J.E., WOOD, T.C., PANWAR, H.S. \& SEIDENSTICKER, J. 2013b. Gene flow and demographic history of leopards (Panthera pardus) in the central Indian highlands. Evol. Applic. 6: 949-959

FRANKHAM, R., BALLOU, J.D. \& BRISCOE, D.A. 2004. A primer of conservation genetics. Cambridge University Press.

HAAG, T., SANTOS, A.S., SANA, D.A., MORATO, R.G., CULLEN, L., CRAWSHAW, P.G., DE ANGELO, C., DI BITETTI, M.S., SALZANO, F.M. \& EIZIRIK, E. 2010. The effect of habitat fragmentation on the genetic structure of a top predator: loss of diversity and high differentiation among remnant populations of Atlantic forest jaguars (Panthera onca). Mol. Ecol. 19: 4906-4921.

HENSCHEL, P., HUNTER, L.T.B.\& COAD, L., Abernethy, K.A. \& MÜHLENBERG, M. 2011. Leopard prey choice in the Congo basin rainforest suggests exploitative competition with human bushmeat hunters. $J$. Zool., Lond. 285: 11-20.

KIMURA, M. 1980. A simple method for estimating evolutionary rate of base substitutions through comparative studies of nucleotide sequences. J. Mol. Evol. 16: 111-120.

KIMURA, M. \& WEISS, G. 1964. The stepping stone model of population structure and the decrease of genetic correlation with distance. Genetics 49: 561-576.

KUMAR, S., TAMURA, K. \& NEI, M. 1993. MEGA: Molecular Evolutionary Genetics Analysis. Pennsylvania State University, University Park, PA.

LINDSEY, P.A., ROMAN, S.S. \& DAVIES-MOSTERT, H.T. 2009. The importance of conservancies for enhancing the value of game ranch land for large mammal conservation in southern Africa. J. Zool., Lond. 277: 99-105.

LOVERIDGE, A.J., PACKER, C. \& DUTTON, A. 2009. Science and the recreational hunting of lions. In: B. Dickson, J. Hutton \& W.M. Adams (Eds), Recreational hunting, conservation and rural livelihoods, ( $p p$. 108-124). Blackwell Publishing, Oxford.

LU, G. \& MORIYAMA, E.N. 2004. Vector NTI, a balanced all-in-one sequence analysis suite. Brief Bioinform 5 : 378-388.

MARKER, L.L. \& DICKMAN, A.J. 2005. Factors affecting leopard (Panthera pardus) spatial ecology, with particular reference to Namibian farmlands. S. Afr. J. Wildl. Res. 35: 105-115.

NGOPRASERT, D., LYNAM, A.J. \& GALE, G.A. 2007. Human disturbance affects habitat use and behaviour of Asiatic leopard Panthera pardus in Kaeng Krachan National Park, Thailand. Oryx 41: 343351.

RAY, J.C., HUNTER, L. \& ZIGOURIS, J. 2005. Setting conservation and research priorities for African carnivores. WCS Working Paper 24: New York: Wildl. Conserv. Soc. 1203.

REED, D.H. \& FRANKHAM R. 2003. Correlation between fitness and genetic diversity. Conserv. Biol. 17: 230 237. 
SPONG, G., JOHANSSON, M. \& BJORKLUND, M. 2000. High genetic variation in leopards indicates large and long-term stable effective population size. Mol. Ecol. 9: 1773-1782.

STONER, D.C., WOLFE, M.L., RIETH, W.R., BUNNELL, K.D., DURHAM, S.L. \& STONER, L.L. 2013. De facto refugia, ecological traps and the biogeography of anthropogenic cougar mortality in Utah. Divers. Distrib. 19: 1114-1124.

SWANEPOEL, L.H. 2013. Viability of leopards Panthera pardus (Linneaus 1758) in South Africa. Ph.D. thesis, University of Pretoria, Pretoria.
SWANEPOEL, L.H., LINDSEY, P., SOMERS, M.J., VAN HOVEN, W. \& DALERUM, F. 2013. Extent and fragmentation of suitable leopard habitat in South Africa. Anim. Conserv. 16: 41-50.

SWANEPOEL, L.H., LINDSEY, P., SOMERS, M.J., VAN HOVEN, W. \& DALERUM, F. In press. The relative importance of trophy harvest and retaliatory killing of large carnivores: a case study on South African leopards. S. Afr. J. Wildl. Res.

WHITLOCK, M.C. 2000. Fixation of new alleles and the extinction of small populations: drift load, beneficial alleles, and sexual selection. Evol. 54: 1855-1861.

Responsible Editor: M.W. Hayward 